\title{
Chest compressions feedback devices improve qualitative outcomes of the BLS-P course
}

\author{
A.Kuzovlev'1, S. Abdusalamov², A. Tsvetkov², S. Perepelitsa ${ }^{1,3}$ \\ 1- V.A. Negovsky Research Institute of General Reanimatology, Federal Research \\ and Clinical Center of Intensive Care Medicine and Rehabilitology, Moscow, Russia \\ 2- Russian National Resuscitation Council, Moscow, Russia \\ 3 - Imannuel Kant Baltic Federal University, Kaliningrad, Russia
}

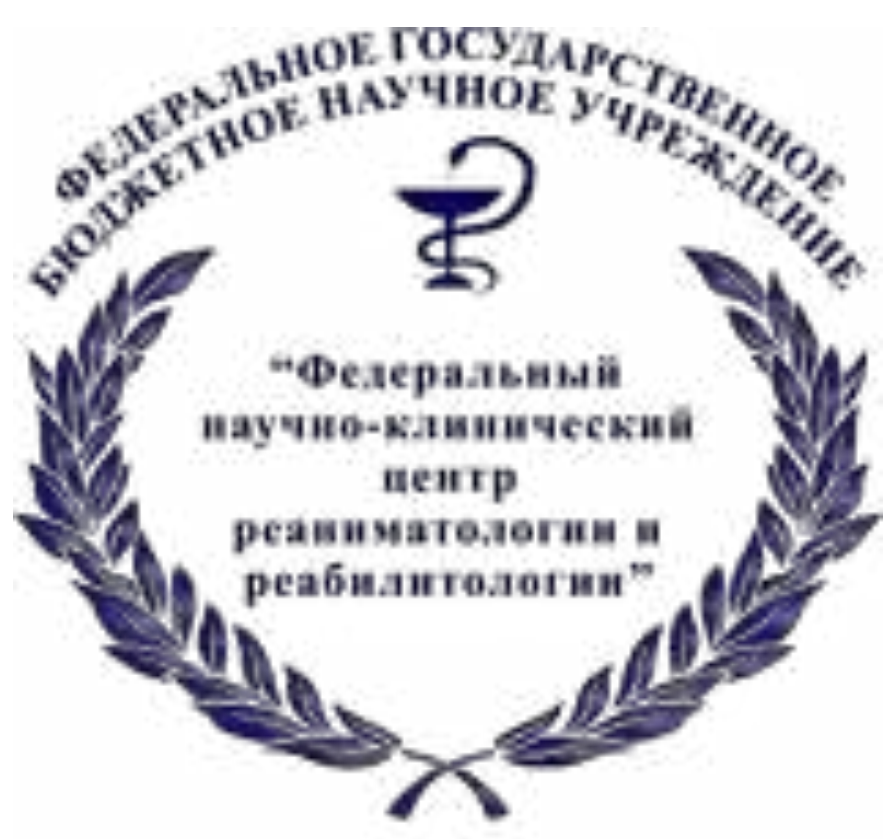

ФНКЦ РР

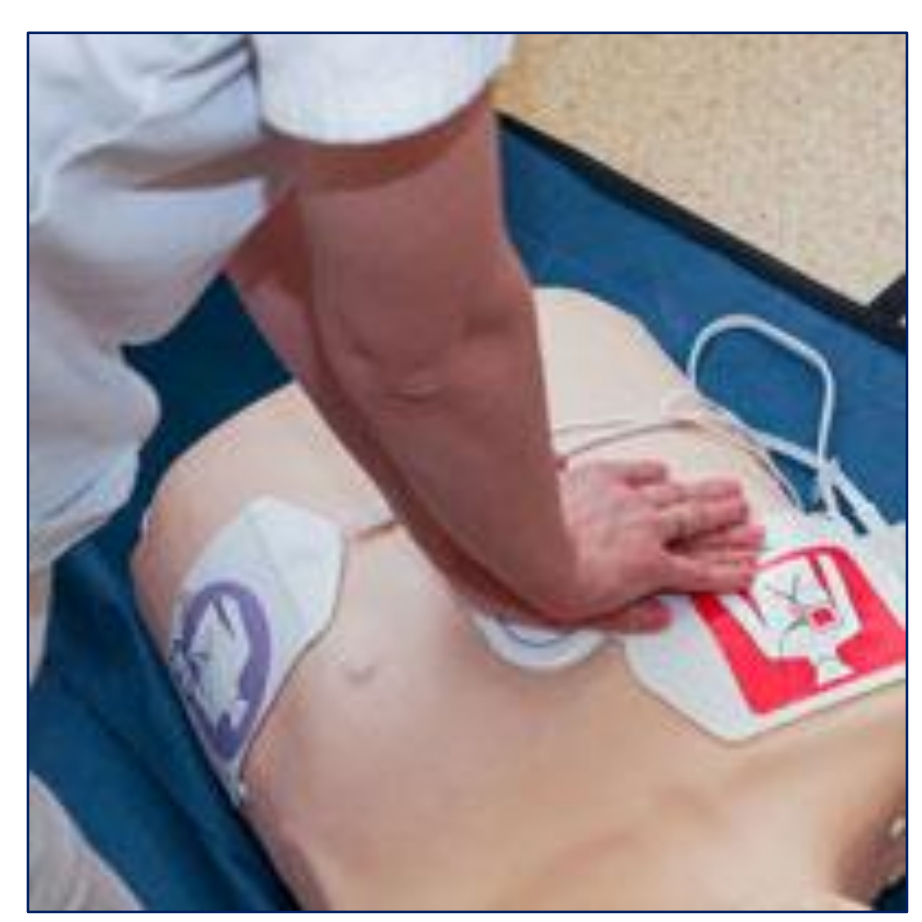

The aim of the study was to assess the influence of chest compressions feedback devices on the qualitative outcomes of the BLS-P course.

Materials and methods. Study was performed in 22 participants of the ERC BLS-P course. Quality of chest compressions (CC) was assessed before and after the course by means of ZOLL R-series defibrillator accelerometer (2 mins recorded cycles of CC). The ERC Guidelines for Resuscitation 2015 were used as reference criteria for CC quality. The same accelerometer was used during the BLS-P course for feedback. The analysis was performed using the ZOLL RescueNet Code ReviewR software. Statistical analysis was done by Statistica 7.0 (Student T-test). Data were presented as mean \pm SD. Difference was considered significant at $P<0.05$.
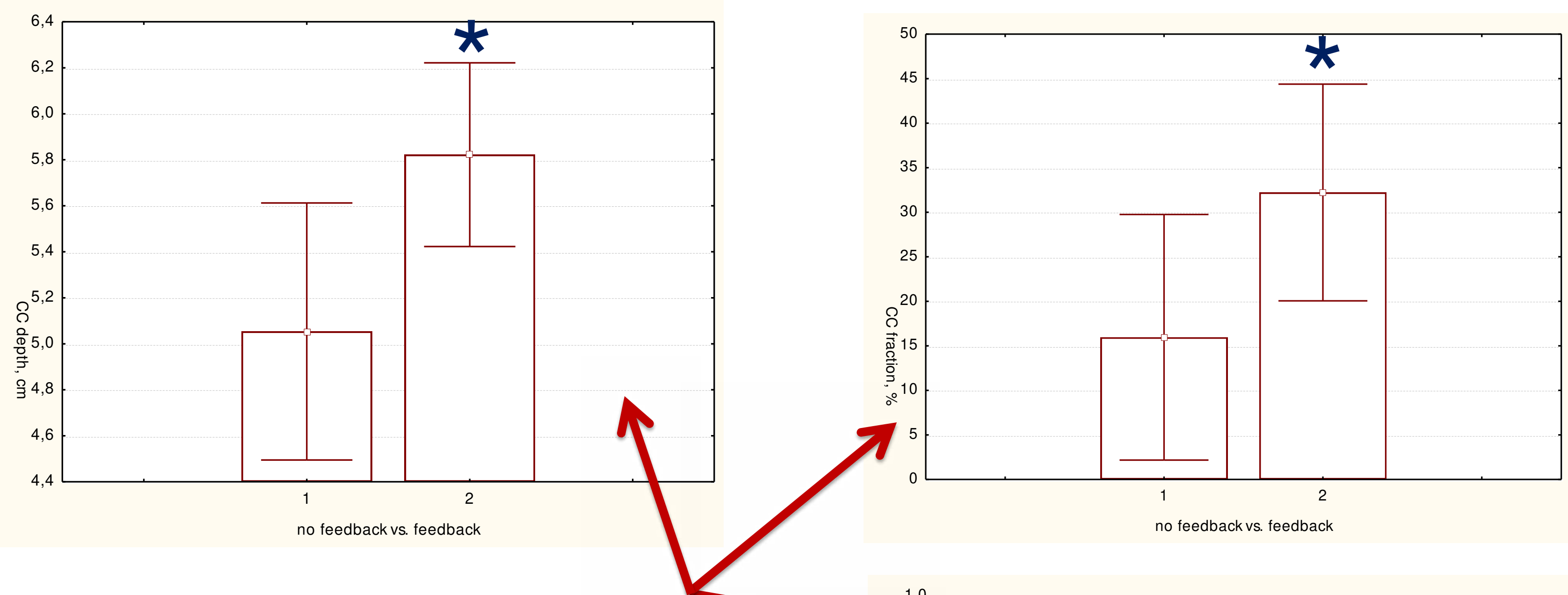

Results. The quality of CC before the course was low and significantly improved in depth, CC fraction and $\mathrm{CC}$ in target in rate after the BLS-P with the use of $\mathrm{CC}$ feedback device:

rate $112,0 \pm 15,7 \mathrm{cpm}$ vs. $111,8 \pm 9,9 \mathrm{cpm}$;

depth $5,0 \pm 1,2 \mathrm{~cm}$ vs. $5,8 \pm 0,9 \mathrm{~cm}$;

CC fraction $15,9 \pm 27,7 \%$ vs. $32,2 \pm 25,9 \%$;

CC in target in depth $40 \%$ vs. $40 \%$;

CC in target in rate $45 \%$ vs. $76 \%$

\section{Conclusions.}

Chest compression feedback devices use during the BLS-P course positively influences the qualitative outcomes of the course: they promote improvement of CC depth, fraction and $\mathrm{CC}$ in target in rate. 